\title{
Headache following Spinal Anaesthesia : A Review on Recent Update
}

\author{
MR ALAM ${ }^{\mathrm{a}}$, MR RAHEEN ${ }^{\mathrm{b}}, \mathrm{KM} \mathrm{IQBAL}^{\mathrm{c}}$, MRA CHOWDHURYd
}

\begin{abstract}
Summary:
Central neuraxial block is an extensively implemented technique in anaesthetic practice. Spinal dural punctures occur deliberately in spinal anaesthesia and inadvertently during attempting epidural blocks. The incidence of disabling headache following dural perforation ranges from 0.3 to $20 \%$ in spinal anaesthesia and may be upto $70 \%$ after accidental dural puncture in epidural anaesthesia. Decreased CSF volume causing reduced pressure and responsive cerebral venodilation due to CSF leakage are deduced as the prime reasons for this post-dural puncture headache (PDPH). The headache is selflimiting and $88 \%$ of it resolves without any interference, if not
\end{abstract}

\section{Introduction:}

Central neuraxial anaesthesia is the sensory neural transmission blockade using local anaesthetics and other additives. It is performed by putting the blocking agents in the vicinity of spinal neural tissues. For spinal anaesthesia (subarachnoid block, $\mathrm{SAB}$ ) a deliberate lumber puncture (LP) occur below $\mathrm{L}_{1}$ in adults ( $\mathrm{L}_{3}$ in child) to access the subarachnoid space avoiding the needle trauma to the cord. ${ }^{1}$ Epidural or extradural anaesthesia offers a wider range of applications throughout the dorsal vertebral column.

a. $\quad \operatorname{Dr}(\mathrm{Lt} \mathrm{Col}) \mathrm{Md}$. Rabiul Alam, MBBS, MCPS, FCPS; Classified Specialist in Anaesthesiology, CMH, Chittagong.

b. Dr Mahbuba Rehana Raheen, MBBS, CMU(BIMDT), DMU(AIMS); Sonologist, Central Diagnostic Lab, Chittagong.

c. Prof Kazi M Iqbal, MBBS, DA, FFARCS(Ireland), FRCA(England), FCPS; Consultant \& Coordinator, Dept of Anaesthesia \& ICU, Apollo Hospitals, Dhaka.

d. Dr (Brig Gen) Md. Rezaul Alam Chowdhury, MBBS, MD(India); Advisor Specialist in Anaesthesiology, CMH, Dhaka.

Address of Correspondence: $\operatorname{Dr}(\mathrm{Lt} \mathrm{Col}) \mathrm{Md}$ Rabiul Alam, Dept of Anaesthesia and ICU, Combined Military Hospital, Chittagong, Chittagong Cantonment, Chittagong, Email: rabiuldr@gmail.com

Received: 1 March, 2010

Accepted: 4 January, 2011 superimposed by any pre-existing or a de novo complication. Anaesthesiologists have been perpetually active in reducing the incidence. Int'l and regional working groups have advocated the use of fine gauge pencil-point needles, delicate bevel orientation techniques, some new drug regimens and various useful and effective measures for the treatment and prevention of $P D P H$. This review considers some contentious aspects of pathogenesis, treatment and prevention of $\mathrm{PDPH}$ and summarises the recommendations incorporated with updated guidelines of American Society of Regional Anesthesia (ASRA) and Society for Obstetric Anesthesia \& Perinatology (SOAP) for the management of PDPH.

(J Bangladesh Coll Phys Surg 2011; 29: 32-40)

\section{Historical Background}

Early days of PDPH: In 1891, Wynter and Quincke aspirated cerebrospinal fluid (CSF) from subarachnoid space for treatment of intracranial hypertension in tubercular meningitis, and would certainly have led to PDPH. In 1898, Karl August Bier, a German surgeon, injected cocaine into subarachnoid space of seven patients, himself and his assistant, Hildebrandt. Bier, his assistant and four of his subjects all described the symptoms associated with PDPH. ${ }^{2}$ Bier surmised correctly that the headache was attributable to loss of CSF.

\section{Factors considered responsible for PDPH}

Anatomical aspects of PDPH: Recent light and electron microscopic studies of human dura mater have contested the conventional concept of fibre direction that it is longitudinal. It described that there are several layers of both collagen and elastic fibres parallel to the surface and do not demonstrate specific orientation. ${ }^{3}$ The outer or epidural surface may have longitudinal fibre direction, but this pattern is not repeated in successive layers. Recent studies have also projected that the posterior dura varies in thickness at different spinal levels within an individual and between individuals. ${ }^{4}$ So, perforation in a thick area is less likely to lead to a CSF leak than in 
a thin area, and may explain the unpredictable consequences.

Needle tip design: Patients who receive spinal anaesthesia with small gauge (24-30G) non-cutting needles generally have a reduced risk of PDPH. ${ }^{5}$ Using smaller Gauge needle with an atraumatic spreading bevel tip can further reduce the incidence of PDPH. Green in 1926 showed that blunt-tipped spinal needles that separate dural fibres and allow recoil with minimal tearing significantly reduce CSF leak and PDPH. ${ }^{6}$ The disadvantages of atraumatic needles include increased cost, lack of pop felt upon piercing the dura and difficulty in penetrating skin due to dull tip. Inadvertent dural perforation by Tuohy needles those are used for applying epidurals, whether the puncture is recognised by CSF visualisation or remained undiagnosed, have been considered as a potential factor to develope PDPH.

Patient factors: Patient-dependent factors of PDPH include age, gender, body mass index (BMI) (low BMI is a risk factor for PDPH), pregnancy and recurrent history of headaches. Race does not seem to be a risk factor for PDPH. ${ }^{7}$

The age group at highest risk is 18 to 40 years, being 34 times that at age of 65 years. ${ }^{8}$ Children younger than 13 years rarely get PDPH due to their lower CSF pressure. There is decreased incidence after 60 years, which may also be related to reduced CSF pressure. ${ }^{9}$ Also, older patients have lower sensitivity of vascular pain receptors and have narrowed route of CSF escape from the epidural space.

Female sex regardless of the age is also a risk factor for PDPH. Women have twice the likelihood compared to men. In general, headache is a common symptom, reported by more than $80 \%$ of women of child-bearing age. As many as $40 \%$ of obstetric patients not receiving any neuraxial anaesthesia complain of headache during the peripartum period ${ }^{10}$, emphasizing the need to rule out other causes of headache.

Obstetric patients are particularly vulnerable to PDPH. They are young, female, pregnant, and many receive epidural procedures for labour and delivery. Another possible predisposing factor to PDPH in pregnancy is lowering of intra-abdominal and epidural pressure after delivery, which promotes extra leakage of $\mathrm{CSF}^{11}$ Stress of labour, changing hormonal level and dehydration may also contribute to increased incidence of PDPH during pregnancy.
Operator factors: The incidence of inadvertent dural puncture during epidural anaesthesia is inversely related to operator experience. ${ }^{12}$ However, sleep deprivation, operator fatigue and the effect of night work may be a confounding variable producing the higher incidence of accidental dural puncture by junior personnel performing epidural analgesia.

\section{Pathogenesis of PDPH}

Dural response to trauma: It is now claimed that the repair of a dural perforation is facilitated by the fibroblastic proliferation from surrounding tissues and promoted more by the damage to pia, arachnoid, the underlying neural structures and presence of blood clot. ${ }^{13}$ So, a careful placement of spinal needle does not promote dural healing, as trauma to adjacent tissue is minimal in this instance. Indeed, it is now observed that bloody taps are less likely to lead to PDPH. ${ }^{14}$

Consequences after cutting tip puncture compared to spreading bevel: Insertion of needle with cutting bevel parallel to the long axis of the spine decreases the likelihood of PDPH as fewer fibres are cut compared with perpendicular orientation. Tearing of the dura may occur upon removal of the needle if it is rotated to a perpendicular orientation after insertion. Bevel orientation is not an issue with atraumatic needles as they separate the dural fibres rather than cutting them allowing them to return to their original position with decreased CSF leakage. ${ }^{6}$

Contact with bone during needle insertion of both cutting and spreading type may lead to tip deformation. Damaged tips could lead to an increase in size of subsequent dural perforation. Recent in vivo studies have demonstrated that mostly the beveled spinal needles get deformed after bony contact than the comparable sized pencil-point needles. ${ }^{15}$

Theories and mechanisms of PDPH: Puncture of dura has the potential to allow the excessive leakage of CSF which leads to intracranial hypotension due to reduction in CSF volume. After development of PDPH, a CSF leak has been confirmed with radionuclide cisternography (Figure-I), radionuclide myelography, manometric studies, epiduroscopy and direct visualization at laminectomy. The adult subarachnoid pressure of $5-15 \mathrm{~cm} \mathrm{H}_{2} \mathrm{O}$ is reduced to $4.0 \mathrm{~cm} \mathrm{H}_{2} \mathrm{O}$ or less. The rate of CSF loss through the perforation $\left(0.084-4.5 \mathrm{ml} \mathrm{s}^{-1}\right)$ is generally greater than the rate of CSF production $\left(0.35 \mathrm{ml} \mathrm{min}^{-1}\right)$, particularly with 
needle sizes larger than 25G. ${ }^{16}$ Gadolinium-enhanced MRI, in the presence of a PDPH, frequently demonstrates 'sagging' of the intracranial structures.

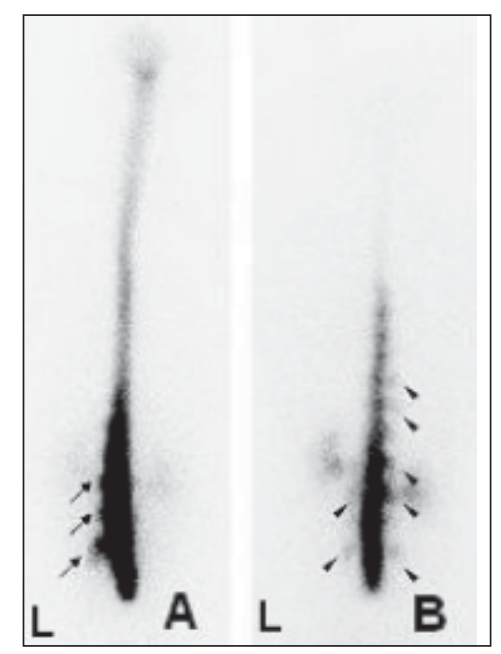

Fig.-1: Radioisotope cisternography images in two patients of PDPH. A. Parathecal activity at lumbar level (arrows). B. Parathecal activity at both lumbar and thoracic levels (arrowheads). L: left side. (Reproduced from Takahashi K, Mima T. Cerebrospinal fluid leakage after radioisotope cisternography is not influenced by needle size at lumbar puncture in patients with intracranial hypotension. CSF Research 2009; 6:5)

There are two possible mechanisms of headache. First, the lowering of CSF pressure causes traction on the intracranial structures in upright position. These structures are pain sensitive, leading to the characteristic headache. Secondly, the loss of CSF produces a compensatory venodilatation as per the Monro-Kellie doctrine. ${ }^{17}$ The consequence of a decrease in CSF volume is a compensatory increase in blood volume. The venodilatation is then responsible for headache.

\section{Incidence of PDPH}

Concerning the needle tip design: The reported incidence of PDPH ranges from $<3 \%$ to $75 \%$, depending on various contributing factors. ${ }^{9}$ This wide range is due to variable degrees of risk between different patient populations and dural puncture techniques. Reducing the size of spinal needle narrower to $31 \mathrm{G}$ has made a significant impact on incidence (Table-I).$^{18}$ However, technical difficulties leading to failure of the spinal anaesthetic are common with needles of $29 \mathrm{G}$ or narrower. Today the use of fine gauge pencil-point needles has largely reduced the incidence of PDPH (Figure - II).
Table I

\begin{tabular}{|c|c|c|}
\hline \multicolumn{3}{|c|}{$\begin{array}{l}\text { Relationship between needle size and } \\
\text { incidence of PDPH. }{ }^{18}\end{array}$} \\
\hline Needle tip design & Needle gauge & $\begin{array}{c}\text { Incidence of } \\
\text { PDPH (\%) }\end{array}$ \\
\hline Quincke & 22 & 36 \\
\hline Quincke & 25 & $3-25$ \\
\hline Quincke & 26 & $0.3-20$ \\
\hline Quincke & 27 & $1.5-5.6$ \\
\hline Quincke & 29 & $0-2$ \\
\hline Quincke & 32 & 0.4 \\
\hline Sprotte & 24 & 0-9.6 \\
\hline Whitacre & 20 & $2-5$ \\
\hline Whitacre & 22 & $0.63-4$ \\
\hline Whitacre & 25 & $0-14.5$ \\
\hline Whitacre & 27 & 0 \\
\hline Atraucan & 26 & $2.5-4$ \\
\hline Tuohy & 16 & 70 \\
\hline
\end{tabular}

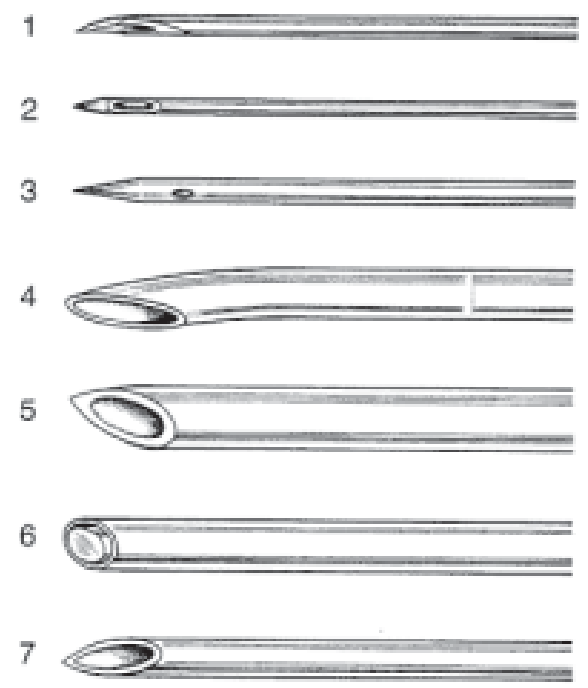

Fig.-2: Graphical representations of needle used for central neuraxial blocks. 1. 26G Quincke ${ }^{\circledR}$ medium cutting bevel; 2. 26G Sprotte ${ }^{\circledR}$ pencil point; 3. 22G Whitacre pencil point; 4. 16G Tuohy needle; 5. 17G Barkers needle; 6. Large gauge spinal needle; 7. $18 \mathrm{G}$ Crawford needle. Needles 5, 6 and 7 are from the Sheffield Anaesthetic Museum and are an indication of the style of spinal needles used in the past. (Reproduced from Geurts JW, Haanschoten MC. Post-dural puncture headache in young patients. Acta Anaesthesiol Scand 1990; 34: 350-3). 
During applying epidurals, the incidence of accidental dural puncture (ADP) is in between 0.7 and 2.6\%. The incidence of ADP with a Tuohy needle, unrecognized by CSF visualization, but subsequently diagnosed by onset of PDPH, is 1.8\%. PDPH may also be even due to a scratch by the tip of a Tuohy needle on the dorsal dura. ${ }^{19}$ The highest incidence of PDPH follows ADP during attempted epidural anaesthesia. An incidence of PDPH as high as 75\% following an ADP using 17/18G Tuohy needles has been documented. ${ }^{20}$ ADP occurs if the dura is perforated by the Tuohy needle or if the Tuohy needle damages the dura which is subsequently perforated by the epidural catheter.

Concerning patients and procedures: The parturients, scrupulously suffer from PDPH following spinal anaesthesia. They are also at particular risk of dural puncture and the subsequent headache because of their sex, young age, and the widespread application of epidural anaesthesia. As many as $26 \%$ of ADPs remain unrecognized at the time of the procedure and first present as PDPH in the early puerperium (Figure-III). Loss of resistance to air (LORA) confers a higher risk of dural puncture than loss of resistance to saline (LORS). The incidence of postpartum headache following epidural labour analgesia without clinically evident dural puncture is $12 \%$. After a puncture with a 16G Tuohy needle, up to $70 \%$ of subjects reported symptoms related to low CSF pressure. Indeed, even up to $39 \%{ }^{21}$ of parturients who have not received neuraxial block report symptoms of a headache following delivery.

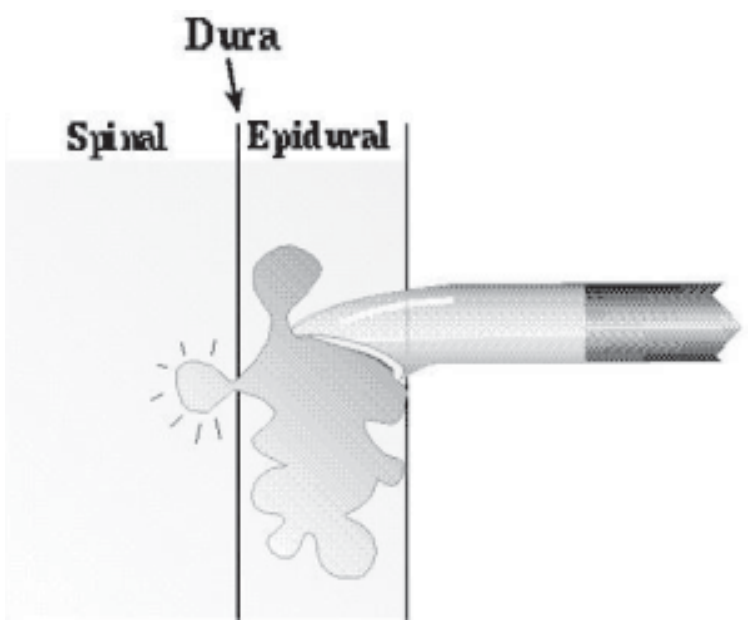

Fig.-3: Unrecognised dural puncture by Tuohy needle. (Reproduced from Joseph Eldor, MD. Combined SpinalEpidural Anesthesia. www.csen.com)
Diagnostic Lumbar Puncture (LP): PDPH after diagnostic LP has an incidence of 6-40\%, (the standard 20 or 22 G Quincke cutting bevel needle may be as high as $40 \%$ ), however this number is reduced to about $5 \%$ when special measures are taken. ${ }^{9}$ It should be acknowledged that the need for adequate CSF flow in diagnostic LPs limits the scope for reduction in needle size, but a needle with an atraumatic tip should be used.

\section{Presentation of PDPH}

Ninety per cent of headaches occur within 3 days of the procedure, and $66 \%$ start within the first 48 h. Rarely, the headache develops between 5 and 14 days after the procedure. Headache may present immediately after dural puncture. ${ }^{22}$ However, this is rare and its occurrence should alert the physician to alternative causes.

Headache is described as severe, 'searing and spreading like hot metal', distributed over the frontal and occipital areas radiating to neck and shoulders. Neck stiffness may be present. Pain is exacerbated by head movement, and in upright posture, and relieved by lying down. An increase in severity of headache on standing is the hallmark of PDPH. Other symptoms includenausea, vomiting, hearing loss, tinnitus, vertigo, dizziness, paraesthesia of the scalp, upper and lower limb pain, visual disturbances and cranial nerve palsies. ${ }^{23}$ Neurological symptoms may precede the onset of grand mal seizures.

Seventy two percent of headaches resolved within 7 days, and $87 \%$ had resolved in 6 months (Table-II). ${ }^{24}$ In a minority of patients the headache can persist even for as long as 1-8 yr. It is interesting to note that even PDPHs of this duration have been successfully treated with an epidural blood patch. ${ }^{25}$

Table-II

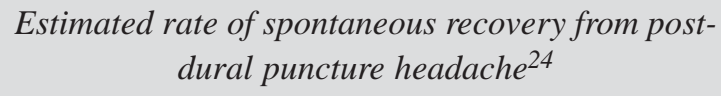

\begin{tabular}{lc} 
Duration (days) & Percentage recovery \\
\hline $1-2$ & 24 \\
$3-4$ & 29 \\
$5-7$ & 19 \\
$8-14$ & 8 \\
$3-6$ weeks & 5 \\
$3-6$ months & 2 \\
$7-12$ months & 4 \\
\hline
\end{tabular}


Diagnosis and differential diagnosis: The history of deliberate or ADP, symptoms of postural headache, neckache and presence of neurological signs, usually guide the diagnosis. In case of doubt, additional tests may confirm the clinical findings. An MRI may demonstrate: diffuse dural enhancement with evidence of a sagging brain; descent of the brain, optic chiasm, and brain stem; obliteration of the basilar cisterns; and enlargement of the pituitary gland. A diagnostic LP may reveal a low CSF opening pressure or a 'dry tap', a slightly raised CSF protein and lymphocyte count. CT myelography or thin section MRI ${ }^{26}$ can be used to locate the spinal source of the CSF leak. It is important to consider alternative diagnoses as serious intracranial pathology may pretend as a PDPH. Diagnoses that may masquerade as PDPH are shown in Table-III. ${ }^{18}$

Table-III

\section{Differential diagnosis of post-dural puncture headache ${ }^{18}$}

Viral, chemical or bacterial meningitis

Intracranial haemorrhage

Cerebral venous thrombosis

Intracranial tumour

Non-specific headache

Pituitary apoplexy

Cerebral infarction

Uncal herniation

Sinus headache

Migraine

Drugs (e.g. caffeine, amphetamine)

Pre-eclampsia

Approach to the problems and management principle

Over $85 \%$ of cases resolve with no treatment within 6 weeks (Table-III). However, a report identified 49 methods for treating PDPH. ${ }^{27}$ There appears to be no limit to the imagination of physicians in treatments offered for it.

\section{General measures}

Reassurance appears as an effective remedy to the patients with PDPH. Patients may reveal a wide range of emotional responses from misery and tears to anger and panic. Obstetric patients are particularly unfortunate should they develop this complication, as they expect to feel well and happy and to be able to look after their new baby. ${ }^{23}$ It is important to give the mother a thorough explanation of the reason for headache, the expected time course, and the therapeutic options available.

Supportive therapy such as bed rest, rehydration, acetaminophen, non-steroidal anti-inflammatory drugs, opioids, and antiemetics may control the symptoms and so reduce the need for more aggressive therapy, but may not provide complete relief. ${ }^{28}$ But there is no point in administering fluids to a patient who is already appropriately hydrated. ${ }^{59}$

Posture that is comfortable is often identified by the patients without intervention of an anaesthetist and it is the supine position. The prone position has been advocated as it raises the intra-abdominal pressure, which is transmitted to epidural space and may alleviate the headache, although it is not comfortable for many as well as post-partum patients. ${ }^{29}$

Abdominal binders raise the intra-abdominal pressure which is transmitted to epidural space and may relieve the headache. Unfortunately, tight binders are uncomfortable and are seldom used in current practice. ${ }^{30}$ There are few centres that would recommend this approach.

\section{Theories that lead to different management}

The main objective of the management of $\mathrm{PDPH}$ is interfering the CSF leakage. This can be achieved by the following specific approaches: (i) replacement of the lost CSF, (ii) sealing of the puncture and (iii) controlling the cerebral vasodilatation.

Caffeine is a CNS stimulant that produces cerebral vasoconstriction. It is available in an oral and i.v. form. Its enteral absorption is quick with a peak level within 30 min. The dose for PDPH now recommended is 300$500 \mathrm{mg}$ of oral or i.v. caffeine once or twice daily. ${ }^{31}$ One cup of coffee contains about 50-100 mg of caffeine and soft drinks contain 35-50 mg.

DDAVP (desmopressin acetate), i.m. before lumbar puncture is an option to reduce the incidence of $\mathrm{PDPH}$. Its long-lasting antidiuretic and vesoconstricting action to restore CSF volume and pressure, and influence on increasing factor VIII and von Willebrand factor favouring quick sealing of dural perforation are thought to have role on relieving $\mathrm{PDPH} .^{32}$ 
ACTH (adrenocorticotrophic hormone) ${ }^{33}$ has also been used as an infusion (1.5 $\mu \mathrm{g} \mathrm{kg}^{-1}$ ), but inadequate statistical analysis prevents assessment of the value of ACTH.

Sumatriptan is a $5-\mathrm{HT}_{1 \mathrm{D}}$ receptor agonist that promotes cerebral vasoconstriction, in a similar way to caffeine. It is advocated for the management of migraine and recently, for PDPH. ${ }^{34}$ Nanatriptan, zolmitriptan and rizatriptan are newer related drugs.

Theophylline administered orally or i.v. relieved symptoms of PDPH probably through its cerebral vasoconstrictive effects. ${ }^{35}$

Hydrocortisone i.v. has been used successfully after ADP by Tuohy needle. The outcome was good after failed conservative measures. ${ }^{36}$

Mirtazapine, a 5- $\mathrm{HT}_{1}$ receptors (notably $5-\mathrm{HT}_{1 \mathrm{~B} / 1 \mathrm{D}}$ ) agonist has recently been tried to relief PDPH. It constricts dilated cerebral vessels and in addition, potentiates endogenous opioid systems. ${ }^{37}$

Gelatin powder (Gelfoam) and Fibrin glue has been proposed to repair spinal dural perforations. Cranial dural perforations are frequently repaired successfully with it. It may be placed blindly or using CT-guided percutaneous injection. ${ }^{38}$ There is, however, a risk of development of aseptic meningitis with this procedure.

Epidural, intrathecal and parenteral opioids have been advocated by number of authors. ${ }^{39}$ But a controlled trial of intrathecal fentanyl as prophylaxis found no evidence of reduction in incidence of PDPH after LP with a 25gauge spinal needle. ${ }^{40}$

Intrathecal catheter placement through the ADP with a Tuohy needle may provoke an inflammatory reaction that will seal the hole. Evidence to support this claim is conflicting. ${ }^{41}$ However, neurological complications preclude its usage.

Pregabalin, an anti-epileptic drug and a structural analogue of GABA have been tried recently and it caused a significant decrease in the difficult and severe PDPH's. ${ }^{9}$

Neural blockades of sphenopalentine ganglion and bilateral greater occipital nerves have been also applied recently for the minimal invasive and successful treatment of severe PDPH which does not respond to conservative treatment. ${ }^{42}$
Acupuncture is recognised as useful in the treatment of headaches of multiple aetiologies. ${ }^{43}$ It is safe, has few risks and is minimally invasive in the hands of trained providers.

Surgical closures of dural perforation in instances of persistent CSF leaks, that are unresponsive to other therapies, have been reported with successful outcome. ${ }^{44}$ This is clearly a last resort of treatment.

\section{Special notes on EBP}

After the observation that 'bloody taps' were associated with a reduced headache rate, ${ }^{14}$ the concept of epidural blood patch (EBP) has developed.

Procedure is simple with the patient in lateral position; the epidural space is located with a Tuohy needle at the level of supposed dural puncture or an intervertebral space lower. The operator should be prepared for the presence of CSF within the epidural space. Twenty to $30 \mathrm{ml}$ of blood is then taken from the patient's arm and injected slowly through the Tuohy needle. At conclusion, the patient is asked to lie still for one or, preferably, $2 \mathrm{~h},{ }^{45}$ and is then allowed to walk. Contraindications are the presence of fever, infection on the back, coagulopathy, or patients' refusal and also include those that normally apply to epidurals.

The fate the blood patch has been assessed and reported by using either radiolabelled red cells or an MRI scan. ${ }^{46}$ The mean spread of $14 \mathrm{ml}$ of blood is 6 spinal segments cephalad and 3 segments caudad regardless of the bevel direction of Tuohy needle. After 7 days, a widespread fibroblastic activity and collagen formation have demonstrated in animal studies. ${ }^{47}$ Fortunately, the presence of blood does not initiate an inflammatory process and no evidence of axonal oedema, necrosis or demyelination.

Outcome of EBP showed a success rate of 70-98\%. ${ }^{48}$ If an EBP fails to resolve the headache, repeating it has a similar success rate. Failure of the second patch and repeating a third or fourth one has been reported. However, in the presence of persistent severe headache, an alternative cause should be considered.

Prophylactic EBP is an attractive option where the known incidence of PDPH is high, such as in parturients. The blood patching is performed before the onset of symptoms. Controlled trials have confirmed the benefit of prophylactic patching. ${ }^{49}$ A greater volume of blood 
is needed to produce a successful patch compared with a late patch to avoid patch separation.

Epidural saline patch: Concerns have been expressed about the potential danger of an autologous EBP. As saline is relatively inert and sterile, and thought to have same mass effect, epidural saline appears to be an attractive alternative. There have been many regimens proposed for this therapy. One is to inject $40 \mathrm{ml}$ of saline into the epidural space, and then an infusion of $40 \mathrm{ml} /$ hr over next $12-24 \mathrm{hr}^{50}$

Epidural dextran: Some observers have considered the epidural administration of Dextran $40 .{ }^{51}$ The studies conclude that the high molecular weight and viscosity of Dextran 40 slows its removal from the epidural space. The sustained tamponade around the dural perforation allows spontaneous closure.

Caudal epidural saline infusion has been used in PDPH which reduced the need for a blood patch or a saline epidural infusion. ${ }^{52}$

\section{Prevention of PDPH}

Needle tip design: The Quincke type is the standard tip-holed needle with a medium cutting bevel (needle1, Figure-II). Then the 'pencil-point' or 'atraumatic' needles were developed, though in truth they are neither. Among those the Sprotte needle (needle 2, Figure-II) has a 'conical' tip and the tip of Whitacre needle (needle3, Figure-II) is 'diamond' shaped. Clinical and laboratory ${ }^{53}$ studies have confirmed that pencil-point tip-holed needles produce fewer PDPHs than medium bevel cutting needles. ASA guidelines 2007 have recommended that the pencil-point needles should be used instead of cutting-bevel needles to minimize the risk of PDPH. ${ }^{54}$ However, these needles also have their limitations, such as obstruction of the delivery port by tissues affecting both cerebrospinal fluid flash back and drug delivery. In side-holed pencil-point needles, increasing the size of the lateral hole has led to mechanical complications, such as tip bending. A new spreading beveled tip-holed spinal needle has been designed by Jahangir SM to overcome the disadvantages of all the currently used spinal needles. ${ }^{55}$

Bevel orientation to dural fibres: There are many clinical, and laboratory, ${ }^{56}$ studies that lend credence to the hypothesis that parallel bevel orientation to dural fibres of a spinal or epidural needle leads to a reduction in the incidence of PDPH. A delicate bevel orientation technique is postulated that it influences to produce a somewhat 'self-sealing' pattern of dural perforation (Figure-IV). But this technique is not yet accepted and recommended by any recognised authority of anaesthesiologists' professionals.

Limitations of fine bore spinal needles: Fine gauge spinal needles, 29G or narrower, are technically more difficult to use, and for SAB at least, are associated with a high failure rate. A balance has to be struck between the risks of PDPH and technical failure. 25G, 26G and $27 \mathrm{G}^{57}$ needles probably represent the optimum needle sizes.

\section{Conclusions:}

Dural puncture procedures are commonly performed by various medical practitioners. The PDPH is a common complication resulting from intentional or accidental dural punctures. Patients who experience a PDPH should not be taken lightly. Data obtained from the ASA's closed claims analysis project showed that this is the third most common reason for litigation in obstetric anaesthesia. ${ }^{58}$ Anyone being treated for a PDPH should receive reassurance as well as a full and frank discussion of treatment options.

The incidence of PDPH varies depending on various contributing factors which can be technical or patient dependant. Clinical diagnosis aided by history is the most important form of diagnosing PDPH; however, imaging may be done to exclude other causes of headache. The prime goal of treating PDPHs is restoring the CSF volume and pressure. Hydration and bed rest do little to prevent PDPH.

Analgesia plays a role in management of PDPHs, starting from mild analgesics initially, progressing to narcotics depending on severity of the headache. Other interventions include intravenous caffeine, intravenous theophylline, oral pregabalin, bilateral greater occipital nerve block, sphenopalentine ganglion block, caudal epidural saline infusions, epidural blood patch; however further randomised controlled trials are still needed to establish true roles of other treatment methods such as acupuncture, i.v. hydrocortisone, oral mirtazapine and caudal epidural saline infusions.

Using tip-holed spreading beveled spinal needle is mandatory to prevent the incidence of PDPH in intentional dural puncture procedures. Contacts of 
needle tip with bones have to be avoided carefully. Development of operator skill in case of epidurals is also essential to reduce the incidence. Lose of resistance to saline technique is preferred to that of air during application of epidurals. Physicians have to consider the accidental unrecognized dural puncture during managing the post-procedural complications.

Epidural blood patch is the most effective form of managing severe headaches. Other therapies that have been offered have not always arisen through the application of logic or reasoning. ${ }^{59}$ If PDPH persists untreated, may predispose to devastating complications such as subdural haematoma, herniation and even death, therefore prompt diagnosis and treatment is mandatory. It is wise to consider other causes of the headache before applying alternative and invasive therapeutic options.

\section{References:}

1. Cook TM, Counsell D. Major complications of central neuraxial block: Report on the Third National Audit Project of the Royal College of Anaesthetists; BJA 2009 102(2):179190.

2. Wulf HF. The centennial of spinal anesthesia. Anesthesiology 1998; 89: 500-6.

3. Fink BR, Walker S. Orientation of fibers in human dorsal lumbar dura mater in relation to lumbar puncture. Anesth Analg 1989; 69: 768-72.

4. Reina MA, de Leon-Casasola OA. An in vitro study of dural lesions produced by 25-gauge Quincke and Whitacre needles evaluated by scanning electron microscopy. Reg Anesth \&Pain Med 2000; 25: 393-402.

5. Seupal RA. Sommerville GG, Viscurci et al. Prevalence of PDPH after ED performed LP. J Emergency Med 2005; 23: 913-5.

6. Rohit Bakshi, Laszlo L. Mechtler. MRI findings in Lumbar puncture headache syndrome. Clinical Imaging 1999; 23: 7376.

7. Flaatten H, Krakenes J, Vedeler C. Post-dural puncture related complications after diagnostic lumbar puncture, myelography and spinal anesthesia. Acta Neurol Scand 1998; 98: 445-51.

8. Velde MV, Schepers R, N Berends. 10 years of experience with dural punctures and PDPH in Obstetric anaesthesia department. Int'l J of Obs Anaes 2009; 17: 329-335.

9. Beyazit Zencira. PDPH \& Pregabailin. $J$ of Pain Research 2010; 3: 11-14.

10. Kenneth D. Candido, Rom A. Stevens. Post dural puncture headache: Pathophysiology, prevention and treatment. Best Practice \& Research Clinical Anaesthesiol 2003; 17: 451469.
11. Gordon H. Morewood. A rational approach to cause, prevention and treatment of postdural puncture headache. Can Med Assoc J. 1993; 149: 1087-1089.

12. Reynolds F. Dural puncture and headache. BMJ 1993; 306: 874-6.

13. Keener EB. An experimental study of reactions of the dura mater to wounding and loss of substance. J Neurosurg 1959; 16: 424-47.

14. Gormley JB. Treatment of post-spinal headache. Anesthesiology 1960; 21: 565-6.

15. Parker RK, White PF. A microscopic analysis of cut-bevel versus pencil-point spinal needles. Anesth Analg 1997; 85: 1101-4.

16. Ready LB, Cuplin S, Haschke RH. Spinal needle determinants of rate of transdural fluid leak. Anesth Analg 1989; 69: 45760.

17. Grant R, Condon B, Hart I. Changes in intracranial CSF volume after lumbar puncture and their relationship to postLP headache. J Neurol Neurosurg Psychiatry 1991; 54: 4402.

18. Turnbull DK, Shepherd DB. Post-dural puncture headache: pathogenesis, prevention and treatment. BJA 2003; 91(5): 718729.

19. Hedge HV, Santhosh MCB, Rao RP. Post-dural puncture headache after unrecognised dural puncture. Update in Anaesthesia. 2009; 25(1): 51-52.

20. Melanie T, Michael J. Management of PDPH in Obstetric patients. Current opinion in Anaesthesiology 2008; 21: 288292.

21. Stein G, Morton J, Marsh A. Headaches after childbirth. Acta Neurol Scand 1984; 69: 74-9.

22. Weir EC. The sharp end of the dural puncture. Br Med J 2000; 320: $127-8$.

23. Carrero EJ, Agusti M, Fabregas N. Unilateral trigeminal and facial nerve palsies associated with epidural analgesia in labour. Can J Anaesth 1998; 45: 893-7.

24. Costigan SN, Sprigge JS. Dural puncture: the patients' perspective. A patient survey of cases at a DGH maternity unit 1983-1993. Acta Anaesthesiol Scand 1996; 40: 71014.

25. Klepstad P. Relief of postural post-dural puncture headache by an epidural blood patch 12 months after dural puncture. Acta Anaesthesiol Scand 1999; 43: 964-6.

26. Vakharia SB, Thomas PS. Magnetic resonance imaging of cerebrospinal fluid leak and tamponade effect of blood patch in postdural puncture headache. Anesth Analg 1997; 84: 58590.

27. Tourtellotte WW, Haerer AF. Lumbar puncture headaches. Springfield, Illinois: Charles C. Thomas, 1964. 
28. Flaatten H, Rodt S, Rosland J, Vamnes J. Postoperative headache in young patients after spinal anaesthesia. Anaesthesia 1987; 42: 202-5.

29. Jones RJ. The role of recumbancy in the prevention and treatment of postspinal headache. Anesth Analg 1974; 53: 788-95.

30. Mosavy SH, Shafei M. Prevention of headache consequent upon dural puncture in obstetric patient. Anaesthesia 1975; 30: 807-9.

31. Camann WR, Murray RS, Mushlin PS. Effects of oral caffeine on postdural puncture headache. A double-blind, placebocontrolled trial. Anesth Analg 1990; 70: 181-4.

32. Hansen PE, Hansen JH. DDAVP, a synthetic analogue of vasopressin, in prevention of headache after lumbar puncture and lumbar pneumoencephalography. Acta Neurol Scand 1979; 60: 183-8.

33. Collier BB. Treatment for post-dural puncture headache. BJA 1994; 72: 366-7.

34. Hodgson C, Roitberg-Henry A. The use of sumatriptan in the treatment of postdural puncture headache. Anaesthesia 1997; 52: 808 .

35. Schwalbe SS, Schifmiller MW, Marx GF. Theophylline for PDPH. Anesthesiology 1991; 75: A1082.

36. Neves JF, Vieira VL, Saldanha RM. Hydrocortisone treatment and prevent post-dural puncture headache: case reports. Rev Bras Anestesiol. 2005; 55(3): 343-9.

37. Michael JS. Shung-Tai Ho, Mirtazapine Relieves Postdural Puncture Headache; Anesth Analg 2008; 107: 346.

38. Patel MR, Caruso PA, Yousuf N. CT-guided percutaneous fibrin glue therapy of cerebrospinal fluid leaks in the spine after surgery. Am J Roentgenol 2000; 175: 443-6.

39. Eldor J. Opiate treatment of post-dural puncture headache. Acta Anaesthesiol Scand 1995; 39: 1140.

40. Devcic A, Sprung J, Patel S. PDPH in obstetric anesthesia: comparison of 24-gauge Sprotte and 25-gauge Quincke needles and effect of subarachnoid administration of fentanyl. Reg Anesth 1993; 18: 222-5.

41. Wilhelm S, Standl T, Burmeister M. Comparison of continuous spinal with combined spinal-epidural anesthesia using plain bupivacaine $0.5 \%$ in trauma patients. Anesth Analg 1997; 85: 69-74.

42. Suna Akin Takmaz. Treatment of Post dural puncture headache with bilateral greater occipital nerve. Headache Journal Compilation 2010. American Headache Society.

43. Chochrane. Collaborative database search. Acupuncture for idiopathic headache. Reviews 2001, 1: CD0012218.
44. Harrington H, Tyler HR, Welch K. Surgical treatment of postlumbar puncture dural CSF leak causing chronic headache. Case report. J Neurosurg 1982; 57: 703-7.

45. Martin R, Jourdain S, Clairoux M, Tetrault JP. Duration of decubitus position after epidural blood patch. Can J Anaesth 1994; 41: 23-5.

46. Beards SC, Jackson A, Griffiths AG, Horsman EL. Magnetic resonance imaging of extradural blood patches: appearances from 30 min to 18 h. BJA 1993; 71: 182-8.

47. Lander CJ, Korbon GA. Histopathologic consequences of epidural blood patch and epidurally administered Dextran 40. Anesthesiology 1988; 69: A410.

48. Abouleish E, Vega S, Blendinger I, Tio TO. Long-term followup of epidural blood patch. Anesth Analg 1975; 54: 459-63.

49. Colonna-Romano P, Shapiro BE. Unintentional dural puncture and prophylactic epidural blood patch in obstetrics. Anesth Analg 1989; 69: 522-3.

50. Stevens R, Jorgennsen N. Successful treatment of dural puncture headache with epidural saline infusion after failure of EBP. Acta Anaesthesiol Scand 1988; 32: 429-31.

51. Souron V, Hamza J. Treatment of postdural puncture headaches with colloid solutions: an alternative to epidural blood patch. Anesth Analg 1999; 89: 1333-4.

52. Cohen C, Pollak P. Caudal saline treatment for post dural puncture headaches. Int'l J of Obs Anaes 2000; 9: 149-150.

53. Cruickshank RH, Hopkinson JM. Fluid flow through dural puncture sites. An in vitro comparison of needle point types. Anaesthesia 1989; 44: 415-18.

54. Practice Guidelines for Obstetric Anesthesia: An Updated Report by the American Society of Anesthesiologists Task Force on Obstetric Anesthesia. Anesthesiology 2007; 106:843-63.

55. Jahangir SM. Tip-holed spinal needle: a new design concept. Reg Anesth Pain Med. 2000; 25(4):403-7.

56. Ready LB, Cuplin S, Haschke RH, Nessly M. Spinal needle determinants of rate of transdural fluid leak. Anesth Analg 1989; 69: 457-60.

57. Kang SB, Goodnough DE, Lee YK, et al. Comparison of 26and 27-G needles for spinal anesthesia for ambulatory surgery patients. Anesthesiology 1992; 76: 734-8.

58. Chadwick HS. An analysis of obstetric anesthesia cases from the American Society of Anesthesiologists' closed claims project database. Int'l J Obs Anesth 1996; 5: 258-63.

59. Schwalbe S. Pathophysiology \& Management of Post-dural Puncture Headache: A Current Review. SOAP Newsletter; Fall 2000. 